Poznań Studies in Contemporary Linguistics 43(2), 2007, pp. 107-131

(C) School of English, Adam Mickiewicz University, Poznań, Poland

doi:10.2478/v10010-007-0015-2

\title{
ENGLISH AS A MIXED V2 GRAMMAR: SYNCHRONIC WORD ORDER INCONSISTENCIES FROM THE PERSPECTIVE OF FIRST LANGUAGE ACQUISITION
}

\author{
MARIT WESTERGAARD \\ University of Tromsø \\ marit.westergaard@hum.uit.no
}

\begin{abstract}
This paper discusses some word order inconsistencies found in present-day English and argues that these may be explained by natural processes in first language acquisition. English is usually assumed to have lost its verb-second (V2) properties in the Middle English period, but the paper argues that English should be considered a mixed V2 grammar, as subject-auxiliary inversion is still a syntactic requirement in all questions and a type of inversion also marginally appears in certain declaratives (with informationally light verbs). Discussing word order variation across Germanic V2 languages as well as some acquisition data, the paper develops an approach to language acquisition and change which is based on micro-cues expressed in the input. This means that there are many types of V2 grammars, which distinguish between different clause types, patterns of information structure, and natural classes of categories. In this model, historical gradualism is seen as successive changes affecting one micro-cue at a time, and the mixed V2 property of English is considered to represent no exceptional case, simply a somewhat more restricted V2 grammar than that of the other Germanic languages.
\end{abstract}

KEYWORDS: Acquisition; change; micro-cues; variation; verb-second.

\section{Introduction}

Unlike the other Germanic languages, which generally have a strict verb second (V2) requirement in all main clauses, Standard English is normally characterized as a non-V2 language. This is illustrated by the classical examples of V2 word order in the German sentences below, where the finite verb appears in front of an adverb in subject-initial declaratives, see (1), and in front of the subject in non-subject-initial declaratives and all questions, as in (2-4). The standard account of this phenomenon is that the verb has 
moved across these elements to the head of the clause, to C, due to some feature requirement on this position (see e.g. den Besten 1977, Vikner 1995). The English glosses/translations clearly indicate that English is not a typical V2 language, at least not of the same kind as German.

(1) Anna liest immer Zeitungen.

*Anna reads always newspapers

(2) Bücher liest sie nur im Sommer.

*Books reads she only in-the summer

(3) Liest sie Zeitschriften?

*Reads she magazines?

(4) Was liest sie im Winter?

*What reads she in-the winter?

In most generative work on $\mathrm{V} 2$, this word order is considered to be the result of a parameter which may be set for either $+\mathrm{V} 2$ or $-\mathrm{V} 2$. Thus, languages are considered to be either V2 languages or non-V2 languages, not something in between. This is also the case within Lightfoot's $(1999,2006)$ cue-based approach to language acquisition and change. According to this theory, linguistic constructions have designated cues which are expressed in certain sentence types in the primary linguistic data that children are exposed to. The cues are abstract pieces of structure, i.e. elements of speakers' Ilanguage ("internalized language", see Chomsky 1986). In Lightfoot (2006: 86) the cue for V2 is formulated as in (5) and described as a piece of structure "where a phrasal category occurs in the Specifier of a CP whose head is occupied by a verb".

$$
\text { Cue for V2 syntax: } \quad{ }_{\mathrm{CP}}\left[\mathrm{XP}{ }_{\mathrm{C}} \mathrm{V} \ldots\right]
$$

For learnability reasons, Lightfoot (1999) argues that Universal Grammar (UG) must require that the verb is obligatorily in $\mathrm{C}$ in this syntactic configuration, as a child adopting (5) as an optional structure, and as a result producing V2 only sometimes, say in Dutch or German, would need negative evidence to reach the target grammar. And negative evidence is arguably not available to children in the acquisition process.

According to the cue-based approach, certain external or language-internal factors may cause statistical shifts in the input to children, which again may cause the frequency of the cue to fall below a critical level for acquisition. The result is that children ignore the cue and develop a grammar without the particular syntactic configuration, although the grammar of the previous generation had it - at least to a certain extent. This means that language change should never be gradual, but abrupt and, in Lightfoot's terminology, "catastrophic", indicating a difference between the I-language grammars of individual speakers of two generations. 
In the history of English, V2 is generally assumed to have been lost during the Middle English (ME) period. This is illustrated by the V2 word order of (6) from early Old English (OE) and the non-V2 in (7) from a text written about 500 years later (examples from Bech 2001: 53 and 56).

$$
\begin{aligned}
& \text { pa he onweg adrifen wæs, cwom he to Cent. } \\
& \text { when he away driven was came he to Kent } \\
& \text { 'When he was driven away, he came to Kent.' }
\end{aligned}
$$

$$
\begin{aligned}
& \text { Soo the kynge retorned hym to the toure ageyne. (Late ME) } \\
& \text { so the king returned him(self) to the tower again } \\
& \text { 'So the king returned to the tower again.' }
\end{aligned}
$$

However, present-day English displays various kinds of inversion in certain clause types, most of them remnants of an earlier V2 grammar. In this paper I point out some of these well-known word order inconsistencies in English and classify it as a mixed V2 language. First and foremost, there is a syntactic requirement for subject-auxiliary inversion in both yes/no-questions and $w h$-questions, and I thus consider all main clause questions to be strictly V2. Second, while V2 is generally assumed to have been lost in declaratives in the history of English, some cases have survived with a certain class of verbs, mainly be and other informationally light verbs. That is, V2 still exists in presentday English, but it is restricted to certain clause and verb types. Within a cue-based approach to language acquisition and change, the following questions may therefore be asked: How can a mixed V2 grammar be learnable? And why could English develop in this way? Answers are sought in a Split-CP model of clause structure in which several cues can be identified for V2 word order, dependent on clause type. This model may thus account for many different $\mathrm{V} 2$ grammars - a welcome result, as a comparison with other Germanic languages reveals that mixed V2 is the rule rather than the exception. The model can also accommodate a system where "optional" V2 within clause types is dependent on information structure. Furthermore, some child language data are investigated, and the survival of certain remnant cases of V2 which cause word order inconsistencies in present-day English are accounted for by children's sensitivity to different clause types, patterns of information structure and natural classes of categories in the acquisition process. This means that the paper does not discuss why loss of V2 takes place historically, but focuses on how the change occurs, i.e. why it is restricted to certain clause types and why V2 survives with certain verb types.

The paper is organized as follows: In the next section, I sketch some word order facts of English, showing that it displays word order variation both across and within clause types and thus, that it could be classified as a mixed V2 grammar. In Section 3, I discuss word order variation across clause types in other Germanic languages, briefly consider children's early acquisition of these mixed word orders, and develop an extended version of Lightfoot's $(1999,2006)$ cue-based approach to acquisition and 
change which is based on a Split-CP model of clause structure and corresponding micro-cues in the input. Section 4 considers mixed V2 within clause types in the history of English and present-day Norwegian dialects, arguing that the distinctions are based on information structure. Some acquisition data are provided, showing that these distinctions are also easily learnable. These findings lead to a discussion why V2 survives in certain cases (with some verbs), which is argued to be due to early acquisition, high frequency and children's sensitivity to natural classes of categories.

\section{English as a mixed V2 language}

As mentioned above, English displays various kinds of inversion. In this section, I focus on two major types, subject-auxiliary inversion in questions, normally referred to as "residual V2" (Rizzi 1996), as well as a type of inversion found in certain declaratives affecting the information structure of the sentence. Examples of the former type are found in (8) and (9), illustrating that this process affects modals and other auxiliaries, which then invert with the subject in yes/no-questions and wh-questions. ${ }^{1}$ Subjectauxiliary inversion is a syntactic requirement in these clause types, which is shown by the obligatory insertion of dummy $d o$ when there is no other auxiliary present, as in (9). This kind of inversion is also required with the copula be, see example (10). It should be noted that the restriction to these verbs is not a feature of this type of inversion per se, but a result of the fact that English no longer has V-to-I movement for lexical verbs (lost in the 16th century, see e.g. Lightfoot 1999). And only what appears in the I(nflection) position may move on to C.

(8a) Is she reading newspapers?

(8b) Can she read academic prose?

(9) What does she normally read?/*What she normally reads?

(10) Where is the paper?/*Where the paper is?

The second kind of inversion that I focus on here is found in declaratives and often called Stylistic Inversion constructions. In this kind of inversion not just the finite verb, but also the non-finite verbs in the verbal cluster (if any) appear before the subject. Birner (1995) discusses a large number of such inversion examples collected from various sources of natural language data. This kind of inversion is restricted to intransitive verbs and mainly centers around the verb be, see (11) from Birner (1995: 242). Alternatively, it occurs in what is typically called Locative Inversion constructions with other verbs

\footnotetext{
${ }^{1}$ There also exists a type of subject-auxiliary inversion in declaratives, e.g. after negative elements as in Never have I seen such an idiot. This type of inversion will be disregarded in this paper.
} 
than be (see e.g. Bresnan 1994), illustrated in examples (12-14) from Birner (1995: $241)^{2}$

(11) An excellent appetizer is the squib ravioli with garlic sauce.

(12) They have a great big tank in the kitchen, and in the tank are sitting all of these pots.

(13) From the lips of a cab driver came an enlightened expression that I thought should be shared.

(14) ...inland from the small, pretty harbor town that's called a haven squats the town of Heart's Rock.

However, Birner avoids the term Locative Inversion, as she shows that non-be inversions are not necessarily locative, illustrated by examples (15) and (16) from Birner (1995: 244-5).

(15) Second, to this rule would apply, optionally, a rule we may call Verb Second...

(16) By syntax (the technical term for sentence structure) is meant, for example: Grouping...

Instead, Birner shows that the possibility to invert the verb and the subject in declaratives depends on information structure. First and foremost, the preposed element may not represent less familiar information than the postposed constituent, i.e. the preposed element must be "discourse-old", while the postposed element must be "discourse-new" (in the sense of Prince 1992). This is illustrated in (17), where the preposed element has been mentioned in the immediately preceding sentence, while the postposed element constitutes new information. In (18), on the other hand, the reply to the question puts the new information first and postposes the discourse-old subject, and the result is an infelicitous sentence. Both examples are from Birner (1995: 237).

\footnotetext{
${ }^{2}$ Like Birner (1995), I exclude here a discussion of similar but distinct inversion phenonomena, such as there-insertion or so-called quotative inversion with verbs of saying. In the latter type of inversion, an example of which is provided in (i), the constituent in front of the verb seems to receive some kind of focus interpretation.

(i) "This is a real scandal!", replied Peter.

Thus, this type of inversion is also related to information structure, but in a different way than the stylistic inversion discussed in this paper, where it is the postverbal subject that represents the new/focused information (see below).
} 
(17) We have complimentary soft drinks, coffee, Sanka, tea and milk. Also complimentary is red and white wine.

(18) A: Mom, where is my gym shirt? I'm late.

B: \#In the hall closet is your gym shirt.

Furthermore, there has been substantial discussion around the type of verb allowing inversion in English declaratives, e.g. unaccusative verbs or verbs of existence/appearance (see Birner 1995 for a thorough discussion). However, in Birner's corpus there are examples of inversion with verbs such as bubble, decay, doze, shriek, work, yawn etc., which are clearly not verbs of existence or appearance. And as also pointed out by Levin and Rappaport-Hovav (1995), the class of unaccusative verbs does not exactly match the type of inversion verbs, as there are unaccusatives that do not seem to be acceptable in inversions, see (19), and occasional inversions occurring with unergative verbs, as shown in (20), both from Birner (1995: 246).

*On the streets of Chicago melted a lot of snow.

(20) From his pulpit preached no less a person than Cotton Mather.

Birner then shows that also the choice of verb in inversion constructions is dependent on information structure, in the sense that it is allowed only with informationally light verbs. She argues for a pragmatic constraint on the information status of the verb in context, which states that "it may not represent new information in the discourse" (Birner 1995: 246). This is the reason that main verb be is so frequent in inversions, as it is inherently light. But other verbs can be made informationally light by the context. By providing examples such as (21) and (22) (from Birner 1995: 253-4), she shows that inversion may apply to an unergative verb such as work when it is mentioned in previous context, as well as to an unaccusative verb like melt when it is inferable from context (cf. example (19)).

(21) I sat alone in an office while across the hall the sound engineer, the pop-eyed, silent but hyper James Hill, worked behind a heavy wooden door lined with what looked like foam-rubber waffles. On the third floor worked two young women $[\ldots]$

(22) The hot August sun beat down on the children as they walked down the street. Johnny was spooning up soggy sherbet out of a cardboard cup; in Maria's sticky hand melted a chocolate-chip ice cream cone.

In this section I have focused on two types of inversion phenomena in present-day English: the well-known syntactic requirement for inversion in all types of questions, affect- 
ing auxiliaries and the copula, and the semi-productive process of inversion in English intransitive declaratives, which, according to Birner (1995), is subject to a pragmatic constraint requiring the verb to be informationally light and the subject correspondingly heavy. Given these word order facts, it is possible to characterize present-day English as a mixed V2 language, a V2 grammar that is restricted to certain clause types and certain verb (and subject) types. That is, the $\mathrm{C}$ position is apparently sometimes filled by the finite verb, but not always. From an acquisition perspective, it is now an important question how the present-day grammar of English can be learnable, given Lightfoot's obligatory cue for V2, formulated in (5) above. It seems that English-speaking children are exposed to conflicting input evidence, some for V2 and some for non-V2. And how could such a system have developed historically?

In the next two sections I attempt to provide some answers to these questions by considering variation across other Germanic V2 languages as well as some acquisition data. I then use an extended version of Lightfoot's $(1999,2006)$ cue-based approach to acquisition and change to account for these word order facts. In Section 3, I discuss the restriction on the V2 phenomenon to certain clause types, and in Section 4, the restriction within clause types (to variation dependent on information structure).

3. Word order across different clause types

\subsection{Variation}

On closer inspection, it turns out that there is great variation within the family of Germanic languages with respect to V2. As discussed in Westergaard (2007), it is normally not the case even in "classical" V2 languages that all clause types exhibit V2 word order, as is shown by the following examples from Norwegian: While V2 is required in subject-initial declaratives, non-subject-initial declaratives and yes/no-questions, as illustrated in (23-25), verb movement is normally disallowed across an adverb or negation in embedded clauses, as well as across the subject in embedded questions or exclamatives, as shown in (26-28).

(23) Vi reiser aldri til Frankrike./*Vi aldri reiser til Frankrike. we travel never to France

'We never go to France.'

(24) England drar vi ofte til/*England vi ofte drar til.

England go we often to

'England we often go to.'

\footnotetext{
${ }^{3}$ Verb movement across an adverb is occasionally found in some types of embedded clauses in Norwegian, see e.g. Bentzen (2005) and Hróarsdóttir, Hrafnbjargarson, Wiklund and Bentzen (2006).
} 
(25) Reiser dere mye?

travel you.PL much

'Do you travel a lot?'

(26) Det finnes folk [som ikke liker å reise/*som liker ikke å reise]. it exist people who not like to travel

'There are people who don't like to travel.'

(27) Jeg lurer på [hvor hun er nå]/[*hvor er hun nå].

I wonder on where she is now

'I wonder where she is now.'

(28) Så rar du ser ut!/*Så rar ser du ut! how strange you look out

'How strange you look!'

Furthermore, that the three latter clause types do not require verb movement is something that varies from language to language within the V2 family: Icelandic generally has verb movement across negation and adverbs in embedded contexts, see (29) from Hróarsdóttir et al. (2006: 1), modern spoken Afrikaans (MSA) displays verb movement across the subject in embedded questions, see (30) from Biberauer (2002: 37), and Danish has verb movement in exclamatives, illustrated in (31). Thus, this information does not come for free when setting the V2 parameter, which means that children must learn this variation from the input.

(29) Ég veit [af hverju Hedda kaupir oft skó]. (Icelandic) I know why Hedda buys often shoes

'I know why Hedda often buys shoes.'

(30) Ek wonder [wat het hy vandag weer aangevang]? I wonder what has he today again done

'I wonder what he has been up to today.'

(31) Hvor er han sød!

where/how is he sweet

(Danish)

'How nice he is!'

There is also even more word order variation in English than was discussed for Standard English in Section 2. For example, Belfast English displays verb movement in embedded questions, as illustrated in (32), and it also has V2 in imperatives, see (33) (examples from Henry 1994: 274-5). And according to Bhatt (2004), Indian Vernacular English (IVE) is the mirror image of Standard English with respect to subject-auxiliary 
inversion in wh-questions: While main clause questions disallow V2, as shown in (34), embedded questions do in fact display this word order, see (35) (examples from Bhatt 2004: 1020). Note that there is also a difference between the type of embedded question that allows verb movement; while V2 is possible in embedded wh-questions in Indian Vernacular English (as in Modern Spoken Afrikaans), this seems to be restricted to embedded yes/no-questions in Belfast English.

(32) They asked me was I going to the party.

(Belfast English)

(33) Bring you that with you!

(Belfast English)

(34) What he has eaten?

(35) They know who has Vijay invited tonight.

This means that children learning Norwegian, Iclandic, Danish, etc. as well as several varieties of English, will be exposed to conflicting evidence in the input, since the finite verb is not always in the $\mathrm{C}$ position, as required by the cue for $\mathrm{V} 2$ syntax as it was formulated in (5). In the next section we therefore consider some acquisition data.

\subsection{Acquisition}

Investigations of early child data show that children generally have no problem acquiring V2 word order in only some clause types. For example, Clahsen and Smolka (1986) show that, while German-speaking children acquire V2 relatively early in main clauses, this word order is generally not overgeneralized to embedded clauses. Furthermore, an investigation of Norwegian child language in Westergaard $(2006,2007)$ reveals that V2 word order is in place early in those clause types that require it, as illustrated by the non-subject-initial declarative in (36) and the yes/no-question in (37). But so is non-V2, as shown by the embedded question in (38) and the exclamative in (39). ${ }^{4}$

$$
\begin{array}{lll}
\text { så tegne } & \text { æ mamma. } \\
\text { then draw.INF/PRES I } & \text { mommie } \\
\text { 'Then I draw mommie.' } &
\end{array}
$$

$$
\begin{aligned}
& \text { ser du nokka? } \\
& \text { see.PRES you } \\
& \text { 'Domething } \\
& \text { Dou see anything?' }
\end{aligned}
$$

(Ina.02, age 1;10.4)

\footnotetext{
${ }^{4}$ The examples are taken from a corpus of Norwegian child language collected in Troms $\varnothing$ by Merete Anderssen and the author, see e.g. Anderssen (2006).
} 
(38) se her ka Ina gjør.

(Ina.04, age 1;11.22)

look here what Ina does

'Look here what Ina is doing.'

$\begin{array}{ll}\text { kor } & \text { store mage han har. } \\ \text { where/how big stomach he have.PRES }\end{array}$

(Ina.27, age 3;3.18)

'What a big stomach he has!'

Virtually no overgeneralization is found in the data, despite the fact that the different clause types are attested in the input with very different frequencies. For example, in a sample of child-directed speech investigated in Westergaard (2006), yes/no-questions are attested as frequently as $28.4 \%$, while exclamatives only occur in $1.0 \%$ of the input - yet, there seems to be no difference between the two constructions with respect to target-consistent acquisition.

Data from English child language are similar. To my knowledge, no study of English child language has attested any overgeneralization of subject-auxiliary inversion from questions to declaratives (or any other clause type, for that matter), see Radford (1992) and Roeper (1999). And although some English-speaking children produce questions without auxiliaries for a period of time, as illustrated in (40a), Radford shows that it is generally the case that as soon as auxiliaries appear in children's utterances, they also tend to be inverted, as shown in (40b) (examples from the Brown corpus in the CHILDES database, Brown 1973, MacWhinney 2000). Furthermore, once children master subject-auxiliary inversion in questions, this process is not overgeneralized to other verb types. ${ }^{5}$

(40a) what you writing?

(Eve.13, age 2;0)

(40b) Sue \# what are you folding?

(Eve.15, age 2;1)

However, it has been attested that some English-speaking children produce certain whquestions with non-target-consistent, i.e. uninverted, word order for a restricted period of time, as illustrated in (41). This has been given various explanations in the literature, e.g. Radford (1994), Rowland and Pine (2000, 2003), Van Valin (2002), Rowland et al. (2003) etc., but given the fact that this tends to be restricted to modals and specific $w h$ elements, it is generally not attributed to overgeneralization from declaratives.

why we can't find the right one?

(Adam.26, age 3;3.04)

\footnotetext{
${ }^{5}$ Radford (1992: 40) only mentions two possible exceptions, both involving the verb go, one of them provided in (ii). He argues that this is not a case of overgeneralization to lexical verbs, but rather a misanalysis of the verb go as an auxiliary.

(i) goes paci in mouth? (N, 23 months)
} 
We may therefore conclude that children do not have any problem with this kind of conflicting input, where word order varies from clause type to clause type. It thus seems like children in the acquisition process are sensitive to different types of $\mathrm{C}$ heads, and this idea is developed further in the next section.

\subsection{A Split-CP model and language change}

Because of the variation found across V2 languages and children's early acquisition of this, Westergaard (2007) extends Lightfoot's cue-based approach to language acquisition and change to a Split-CP model. The model was originally developed in Westergaard and Vangsnes (2005), but has been somewhat revised in Westergaard (2006, 2007). It is naturally inspired by Rizzi's (1997) original Split-CP model and later work on Italian syntax (e.g. Rizzi 2001, Benincà and Poletto 2004), which assumes that the $\mathrm{CP}$ domain is dominated by a ForceP (expressing illocutionary force) and closed off by a Fin(iteness)P, with various heads in between expressing Focus and Topic relations, see (42):

$$
\text { CP-domain: }{ }_{\mathrm{CP}}\left[\mathrm { Force } ^ { \mathrm { o } } \left[\mathrm { Top } ^ { \mathrm { o } } \left[\mathrm { Foc } ^ { \mathrm { o } } \left[\mathrm { Top } ^ { \mathrm { o } } \left[\mathrm{Fin}_{\mathrm{IP}}^{\mathrm{o}}[\ldots\right.\right.\right.\right.\right.
$$

The model assumed here is in certain ways different from this standard approach to the Split-CP. The crucial aspect of this model for the issue at hand is that the topmost projection in the CP domain in Rizzi's system, the ForceP, is divided into several different projections with different features, depending on clause type. Thus, this is a model with a Split-ForceP. This means that illocutionary force is reflected in the syntactic make-up of the CP-domain, in that e.g. a $w h$-question is an Int(errogative)P, a declarative a Top(ic)P, a yes/no-question a Pol(arity)P, an exclamative an ExclP, etc. The ForceP could be said to come in different flavors, as it were. The distinction between main and embedded clauses is represented as a defective CP-domain in embedded contexts. Thus, embedded declaratives are bare FinPs. Embedded questions are assumed to be bare WhPs, different from the main clause IntPs and PolPs, as they do not have the interrogative force of main questions. This means that all clause types (main or embedded) are different with respect to the syntactic projections available in the $\mathrm{CP}$.

In this model, languages may differ with respect to which $\mathrm{C}$ heads require $\mathrm{V} 2$, which means that the model can account for many different V2 grammars. With respect to acquisition, the functional architecture of this system is assumed to be provided by UG, but, given the variation across languages, the requirement for $\mathrm{V} 2$ in the different clause types must be learned from input. Recall that Lightfoot formulated the cue for V2 syntax in a model with an unsplit CP as in (5), repeated here for convenience.

$$
{ }_{\mathrm{CP}}\left[\mathrm{XP}{ }_{\mathrm{C}} \mathrm{V} \ldots\right]
$$


In the Split-CP model there must then be several cues for V2 syntax, one for each clause type - what I call micro-cues. That is, the cue for $\mathrm{V} 2$ in $w h$-questions is a piece of structure with a finite verb in the head position of the IntP, the cue for V2 in declaratives is a structure with a finite verb in the head of the TopP, the cue for V2 in embedded questions is a finite verb in the head of the WhP, etc. Some examples of these micro-cues are fomulated in (43-45):

Cue for V2 in wh-questions:

Cue for V2 in declaratives:

Cue for V2 in embedded questions:

$$
\begin{aligned}
& \operatorname{IntP}\left[w h_{\text {Int }^{\circ}} \mathrm{V} \ldots\right] \\
& \text { TopP }[\mathrm{XP} \mathrm{Top} \mathrm{V} \text {... }] \\
& { }_{W h P}\left[(w h)_{W h} \mathrm{~V} . . .\right]
\end{aligned}
$$

The Split-CP model can thus account for the variation across V2 languages in the following way: Standard English has the micro-cue for V2 on the $\mathrm{Int}^{\circ}$ and $\mathrm{Pol}^{\circ}$ heads, expressed as subject-auxiliary inversion in $w h$-and yes/no-questions, while it lacks these micro-cues for the heads $\mathrm{Top}^{\circ}, \mathrm{Excl}^{\circ}$ and $\mathrm{Wh}^{\circ}$, accounting for non-V2 word order in declaratives, exclamatives and embedded questions. Belfast English differs from this in that the micro-cues for V2 are expressed in embedded questions and imperatives (the $\mathrm{Wh}^{\circ}$ and $\mathrm{Imp}^{\circ}$ heads). And Indian Vernacular English is the opposite of Standard English with respect to the requirement on the $\mathrm{Int}^{\circ}$ and $\mathrm{Wh}^{\circ}$ heads. A classical V2 language such as Standard Norwegian expresses the micro-cue for the $\mathrm{Int}^{\circ}, \mathrm{Top}^{\circ}$ and $\mathrm{Pol}^{\circ}$ heads, accounting for $\mathrm{V} 2$ in $w h$-questions, declaratives and yes/no-questions. Danish differs minimally from Norwegian in that it also expresses the V2 micro-cue on the exclamative head, while a typical non-V2 language such as Italian lacks all of these microcues. $^{6}$

This means that there is no "global" cue for V2 syntax, but separate cues for each clause type. In Westergaard $(2006,2007)$ it is argued that in the acquisition process, children make a selective search for these cues in the primary linguistic data that they are exposed to, scanning the relevant contexts only. That is, when searching the input for word order cues regarding the IntP, children only consider $w h$-questions, while all other clause types are irrelevant and therefore disregarded. This also means that when children have discovered a micro-cue affecting one $\mathrm{CP}$ head, this will not automatically

\footnotetext{
${ }^{6}$ As presently stated, the model predicts all kinds of variation across clause types to be possible, even a grammar where only embedded questions display V2 and no other clause types, e.g. declaratives or main clause questions. This situation in fact seems to hold for Indian Vernacular English. It is of course possible that there are certain constraints on the word order variation that a language may display across clause types, in which case the model should be restricted accordingly. I consider this to be an empirical question that must be explored by further work on variation, acquisition and change. Note that this means that the degree0 learnability advocated by e.g. Lightfoot (1999), which claims that children scan the primary linguistic data for word order cues only in unembedded contexts, cannot be assumed. See also Westergaard and Bentzen (2007) for further arguments against degree-0 learnability.
} 
be transferred to other heads. Thus we expect to see no overgeneralization of word order from one clause type to another.

This version of the Split-CP model with the corresponding concept of micro-cues in acquisition also has certain consequences for language change. If the acquisition of different word orders for different $\mathrm{CP}$ heads is unproblematic, then a change in one particular functional head should not necessarily have a spill-over effect to other $\mathrm{CP}$ heads. Within this Split-CP framework it would then be expected that word order changes should typically affect only one clause type at a time. This means that what we see in the history of English in fact represents the standard case, with only declaratives being affected by the loss of V2, while this word order is retained as a syntactic process in all questions. According to Vangsnes (2005) and Westergaard (2005b) this also holds for the situation in present-day Norwegian dialects, where only $w h$-questions seem to undergo a loss of $\mathrm{V} 2$, while all other clause types are unaffected, including declaratives and yes/no-questions (see the next section). A third example of this kind of selective loss is found in Henry (1994). She describes a change in progress in Belfast English, where $\mathrm{V} 2$ is being lost in imperatives while it stays unaffected in other clause types, e.g. main and embedded clause questions.

In this section, it has been argued that Lightfoot's cue-based approach to language acquisition and change must be extended to a Split-CP model in order to account for different types of V2 grammars. Assuming that children search selectively for these micro-cues in the input, mixed V2 systems are learnable, and it is in fact unproblematic for English-speaking children that there is V2 in questions but (generally) not in declaratives. A consequence of this is that word order change should typically affect only one clause type, rendering the selective loss of V2 in English declaratives a standard case.

\section{Word order differences within clause types}

\subsection{Variation across languages and the Split-CP model}

In this section I discuss the type of V2 that is normally referred to as Stylistic Inversion, found in some types of English declaratives and which, according to Birner (1995) is dependent on a pragmatic rule that requires the verb to be informationally light. In that connection it should be noted that both $\mathrm{V} 2$ and non-V2 word orders were attested in declaratives already in Old English (OE), as illustrated in (46) and (47), from Kroch and Taylor (1997: 302). At this time V2 word order is also attested in sentences where the whole verbal cluster appears before the subject, as illustrated in (48), from Bech (2001: 53-54). These are similar to the ones that generally survive into present-day English, cf. Section 2.

(46) \& of heom twam is eall manncynn cumen. and of them two is all mankind come 
(47) Ælc yfel he mæg don.

each evil he can do

(48) Đa wurdon geædniwode on ðam eahteoðan geare pa forlætenan cyrcan. then were restored in the eigth year the deserted churches 'Then, in the eigth year, the deserted churches were restored.'

In fact, it seems impossible to find a stage in the history of English which is exclusively V2 in declaratives (see e.g. Swan 1994). In work within generative syntax (e.g. Lightfoot 1999, Kroch and Taylor 1997), it is often argued that this is due to grammar competition, more specifically a mixture of two dialects, a northern one with consistent V2 (due to Scandinavian influence) and a southern one lacking V2. Some speakers had access to both grammars and used both, it is argued, to some extent dependent on sociolinguistic and stylistic factors.

However, the variation between V2 and non-V2 is not random, nor does it seem to be dependent on sociolinguistic factors. As has been noted by many scholars (e.g. van Kemenade 1987; Pintzuk 1991; Kroch and Taylor 1997), V2 is preferred with full DP subjects, as in (46) and (48), while non-V2 predominates in sentences with pronominal subjects, as in (47). A common analysis of this within the generative framework is that pronouns in $\mathrm{OE}$ are clitics that appear in a position higher than $\mathrm{C}$, and that sentences like (47) are therefore only apparent counterexamples to the V2 requirement (e.g. Kroch and Taylor 1997).

In contrast to this, it has been argued both by Bech (2001) and Westergaard (2005a) that the word order choice in $\mathrm{OE} / \mathrm{ME}$ is dependent on information structure, V2 being preferred when the subject conveys new or focused information, and non-V2 when the subject is discourse-given. Thus, non-V2 is naturally linked to pronominal subjects, which are normally given information, while V2 is connected to full DP subjects, which are more likely to convey new information. This analysis follows Bresnan and Nikitina (2003, to appear), who argue that optionality in syntax often leads to the choice of word order being governed by various pragmatic factors.

This kind of word order variation is in fact also attested in other languages. In many present-day Norwegian dialects there is no strict V2 requirement in $w h$-questions, see e.g. Vangsnes (2005). This is illustrated by the example in (49) from the Tromsø dialect, which allows both V2 and non-V2 in wh-questions introduced by the monosyllabic question words, with no significant difference in meaning.

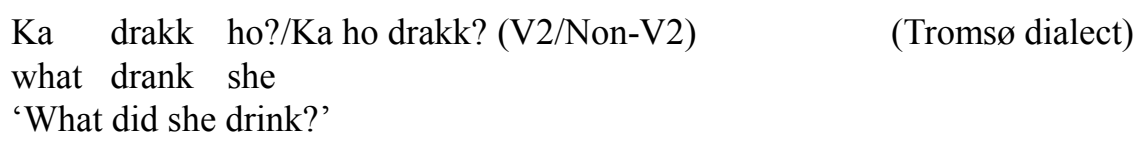


In Westergaard (2003), a sample of spontaneous speech from one adult speaker was investigated, and a truly mixed grammar was attested, with a proportion of approximately $45-55 \%$ V2 vs. non-V2. Moreover, the choice of the two word orders was found not to be random. In the sample there were statistically significant patterns of subject and verb choice related to the two word orders, V2 typically being chosen with the verb be and full DP subjects (or the demonstrative det), and non-V2 with pronominal subjects and any other verb than $b e$, as illustrated in examples (50) and (51).

$$
\begin{aligned}
& \text { kor er mitt fly? } \\
& \text { where is my plane } \\
& \text { 'Where is my plane?' }
\end{aligned}
$$

(INV, file Ole.17)

$$
\begin{aligned}
& \text { kor vi lande henne? } \\
& \text { where we land LOC } \\
& \text { 'Where should we land?' }
\end{aligned}
$$

This finding led to the analysis that V2 was preferred when the subject is discourse new or focused information (often a full DP, but not necessarily), and non-V2 when the subject conveys given information, thus often personal pronouns, which are in a sense inherently given. In Westergaard and Vangsnes (2005) and Westergaard (2006, 2007), this is given a syntactic analysis in terms of a head in the Split-CP model which is lower than the functional projections expressing illocutionary force discussed in the previous section. This projection corresponds to the lower TopP of Rizzi's system, see the structure in (42) above, and accordingly I call it the LowTopP. This functional projection isargued to be sensitive to information structure in that it only attracts elements which are informationally light: That is, a discourse given subject (often a pronoun) may move to its Spec position or an informationally light verb (often be) to its head position. This means that the verb is attracted to this functional projection only when the subject is new or focused information, which accounts for V2 word order only appearing in these cases.

The verb movement seen in declaratives with $\mathrm{V} 2$ in $\mathrm{OE}$ could then be argued to involve the same functional projection as in the examples from the Tromsø dialect, the LowTopP. This would mean that the finite verb could move to the LowTop ${ }^{\circ}$ head, as illustrated in the structure in (52) overleaf. Again this attracts the verb only when the subject is new or focused information and the verb is correspondingly light.

However, the whole verbal cluster may also appear in front of the subject in this type of inversion, e.g. wurdon gecedniwode 'were restored' in sentence (48), which makes it difficult to argue for a head movement analysis of these constructions. But note that the Norwegian mixed word order data in $w h$-questions were analyzed in terms of movement either to the Spec or to the head position of the LowTopP, of informationally light subjects or verbs respectively. I therefore argue for the following syntactic analysis for sentences such as (48) in the history of English: After the new/focused sub- 
ject has moved out of the VP, to SpecTP, the rest of the VP (being informationally lighter than the subject) may undergo remnant movement to the Spec position of the LowTopP, as illustrated in (53).

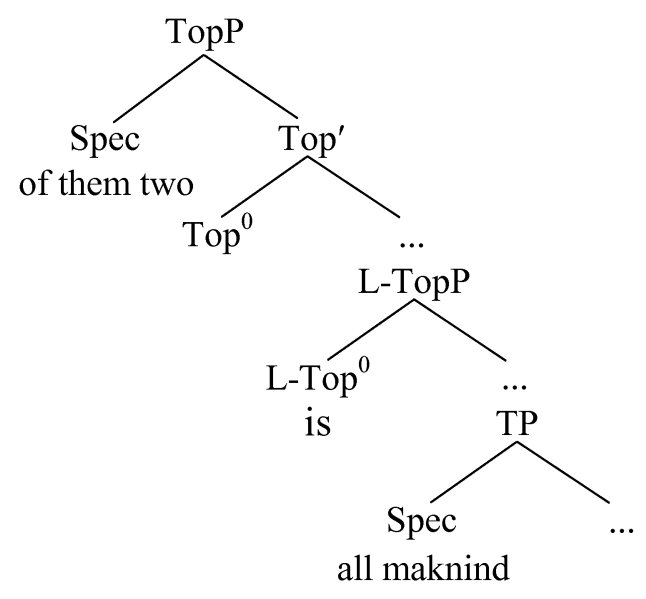

(53)

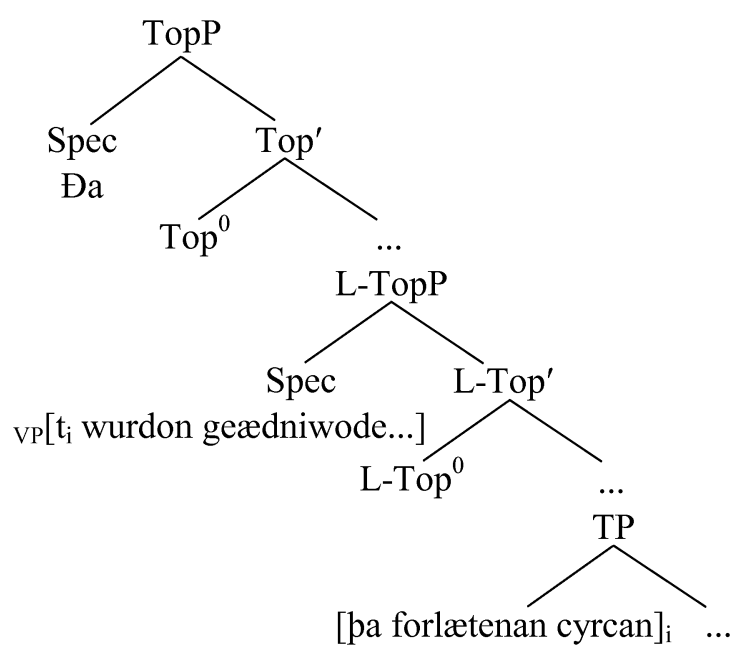

This analysis may then be extended to the present-day examples of stylistic inversion discussed in Section 2, e.g example (12) repeated here for convenience. This means that this type of inversion is not verb movement to $\mathrm{C}$, as in traditional analyses of $\mathrm{V} 2$, but remnant movement of the whole VP (including the trace of the moved subject) to the 
Spec position of the LowTopP, in this case $\left[t\right.$ are sitting]. ${ }^{7}$ This is illustrated by the simplified bracketed structure in (54).

(12') They have a great big tank in the kitchen, and in the tank are sitting all of these pots.

$\ldots$ in the tank $\mathrm{LowTopP}_{\mathrm{VP}}\left[t_{i} \text { are sitting }\right]_{\mathrm{j} T \mathrm{TP}}\left[\mathrm{DP}[\text { all of these pots }]_{\mathrm{i}} t_{\mathrm{j}} \ldots\right.$

In this way the existence of a lower $\mathrm{CP}$ head which is sensitive to information structure may be used to account for word order variation within clause types; $w$ h-questions in Norwegian dialects and declaratives in the history of English.

\subsubsection{Acquisition}

An important question is now how children fare with mixed input such as this in the acquisition process. The Split-CP model and the micro-cues discussed in section 3.3. facilitate acquisition of word order variation across different clause types, but we are now dealing with variation within clause types. And again, according to the cue-based model, the micro-cues should be obligatory. Westergaard (2003) presented some acquisition data on $w h$-questions in the Tromsø dialect and showed that children do not seem to have any problem with this either, as not only do they produce both word orders from an early age, they also use them with the same patterns of subject and verb types as in the adult sample, illustrated in (55) and (56). That is, also in the child data, V2 typically appears with be and full DP subjects and non-V2 with pronominal subjects and non-be.

$$
\text { kor e babyen? (Ina.06, age 2;1.0) }
$$

where be.PRES baby.DEF

'Where is the baby?'

$$
\begin{aligned}
& \mathrm{ka} \mathrm{du} \text { skal finne? } \\
& \text { what you shall find } \\
& \text { 'What do you want to find?' }
\end{aligned}
$$

\footnotetext{
${ }^{7}$ Note that this type of movement is not possible in $w h$-questions in English, as the following sentence is ungrammatical:

(i) *Where are sitting all those girls?

This type of word order is not in principle excluded from the grammar of English, but it happens not to be part of the present-day system. Children are thus never exposed to the cue for such word orders in whquestions, and given the acquisition data and the model of micro-cues discussed in Section 3, children are not expected to transfer word order patterns from one clause type to another.
} 
Children thus seem to have an early sensitivity to information structure. This means that the model must include even finer micro-cues, where distinctions between informationally given and informationally new or focused elements must be specified. The following are examples of how such micro-cues may be formulated, (57a) for $w h$-questions in present-day Norwegian and (57b) for the situation in declaratives in the history of English. In both cases the verb appears in the (head or specifier of) the LowTopP if the subject is marked with a feature indicating that it is new information, here formulated as [+Foc].

(57a) Cue for V2 in wh-questions:

(57b) Cue for V2 in declaratives:

$$
\begin{aligned}
& \operatorname{IntP}\left[w h_{\text {LowTopP }}\left[\operatorname{LowTop}^{\circ} \mathrm{V} \mathrm{XP}_{[+\mathrm{FOC}]}\right] \ldots\right. \\
& \mathrm{TopP}\left[\mathrm{XP} \text { LowTopP }_{\text {LowTop } \left.^{\circ} \mathrm{V}\right]} \mathrm{XP}_{[+\mathrm{FOC}]}\right] \ldots \\
& \text { TopP }\left[\mathrm{XP}_{\text {LowTopP }}\left[\mathrm{vP}\left[t_{i} \mathrm{~V}\right] \mathrm{XP}_{[+\mathrm{FOC}]}\right] \ldots\right.
\end{aligned}
$$

The fact that a mixed grammar like this is acquired so early and easily by children can account for the fact that it survives for several centuries in the history of English. But if this is so simple for children, why does it change? As mentioned above, the Split-CP model is based on micro-cues expressed in children's input, and historical change is considered to take place in small steps, affecting one micro-cue at a time and thus giving the impression that change is gradual. There may therefore be many causes for the loss of V2 in English (and many have been explored in the literature, e.g. van Kemenade 1987; Pintzuk 1991; Kroch and Taylor 1997; Lightfoot 1999; Haeberli 2002; Westergaard 2005a). However, as mentioned above, this issue is outside the scope of this paper. The next section will therefore address the question of why this change is not complete, but simply results in a more restricted version of $\mathrm{V} 2$.

\subsubsection{Language change and children's sensitivity to natural classes of categories}

In this final section of the paper I explore a possible reason why V2 survives in certain cases in English, and why exactly with those verbs that were discussed in Section 2, mainly be and other informationally light verbs. But first I present some data to show that this is not a feature that is specific to English. Westergaard (2005b) investigated a sample of spontaneous speech from another Norwegian dialect (Kåfjord), which is similar to the Tromsø dialect in that it allows both V2 and non-V2 in wh-questions. However, unlike the Tromsø speaker who had a mixed grammar, the Kåfjord speakers in the study use a predominance of non-V2, approximately $85-98 \%$. An investigation of the subject and verb preferences produced reveals that non-V2 occurs with all types of subject and verb combinations, indicating that non-V2 is the default, productive word order in this dialect. V2 only survives in special cases, virtually only with the verb $b e$.

Other languages also provide evidence that $\mathrm{V} 2$ word order is preferred with specific verbs. According to Poletto (2006), as V2 was lost in Romance, it tended to survive 
with auxiliaries as well as with be. Also in Latin, where the verb normally occupies final position, see (58) from Salvi (2005: 24), there are examples of V2, but only with the verb esse 'be'. This is illustrated for a wh-question in (59) and a declarative in (60), from Salvi (2005: 31-2). ${ }^{8}$ As these developments in English, Norwegian and Old Romance are historically unrelated, this indicates that $b e$ has a different status from other verbs in the human grammar.

$$
\begin{array}{lllll}
\text { quo } & \text { me } & \text { in } & \text { silvam } & \text { venatum vocas? } \\
\text { where } & \text { I.ACC } & \text { into } & \text { wood.ACC } & \text { to-hunt you-summon }
\end{array}
$$

'Whither dost thou summon me a-hunting in the woods?'

$$
\begin{aligned}
& \text { An quid est homini Salute melius? } \\
& \text { Q-PART what.N is man.D Salvation.ABL better }
\end{aligned}
$$

'Eh? What's better for a man than Salvation?'

(60) haec enim ornamenta sunt tibi etiam cum aliis communia these. $N$ for distinctions. $N$ are you.D also with others. $A B L$ common 'for these are distinctions which others can claim as well as yourself'

Let us now return to the question why V2 to a certain extent survives in English, and why mainly with $b e$ ? First of all, given the patterns of the mixed grammar in OE/ME, it is not surprising that if $\mathrm{V} 2$ survives at all, it should be with informationally light verbs (and focused subjects), as this is the context that is already linked to V2 in the mixed grammar. But why should V2 survive in certain cases and not be completely lost? This, I would argue, could be related to the language acquisition process, more specifically to early acquisition and high frequencies in child language. And what is early and frequent in child language is presumably less vulnerable to change. In classical V2 languages such as German or Norwegian, be is normally the first verb to be attested in questions and declaratives with verb movement in early child language, and it is also very frequent. In fact, in many studies on German language acquisition, e.g. Clahsen, Penke and Parodi (1993/94), early wh-questions with wo/was 'where/what' and the verb sein 'be', as in example (61), are excluded from V2 counts, as they are so early and frequent that they are assumed to be formulaic at this stage.

$$
\begin{aligned}
& \text { wo is de Kugel? } \\
& \text { where be.PRES the marble } \\
& \text { 'Where is the marble?' } \\
& \text { Target form: Wo ist die Kugel? }
\end{aligned}
$$

\footnotetext{
${ }^{8}$ This could possibly be taken as the beginning of the V2 grammar that was later seen in Old Romance. However, Salvi (forthcoming) argues against this kind of V2 as a forerunner for V2 in Old Romance.
} 
Rowland et al. (2003), who have investigated the wh-questions produced by 12 Englishspeaking children, also find that the copula is an extremely early acquisition in inversion constructions in English child language. ${ }^{9}$ A couple of examples from the Brown corpus are provided in (62) and (63).

$$
\text { what is that? (Eve.15, age } 2 ; 1)
$$

(63) where de> $[/ /]$ where is a man? (Eve.16, age 2;1)

The copula is attested early also in non-subject-initial declaratives, as shown by the following examples from Norwegian child language.

$$
\begin{array}{lll}
\text { der } & \text { er } & \text { mann. } \\
\text { there } & \text { be.PRES } & \text { man }
\end{array}
$$

(Ina.01, age 1;8.20)

(Norwegian)

'There is (a/the) man.'

$$
\begin{array}{lll}
\text { her } & \text { er } & \text { sekken. } \\
\text { here } & \text { be.PRES } & \text { backpack.DEF }
\end{array}
$$

(Ann.03, age $1 ; 10.2)$

'Here is the backpack.'
no er det den.
now be.PRES it that
(Ole.01, age 1;9.10)
'Now it is that one.'

In fact, an investigation of the overall frequency of $b e$ in the early Norwegian child data shows that this verb is attested between $59.2 \%$ and $86.5 \%$ of the time in non-subjectinitial declaratives before approximately age $2 ; 2$, while the corresponding figure for a sample of adult data (child-directed speech) is only $23.5 \%$. This is illustrated in Table 1.

Table 1. Frequency of the verb be in non-subject-initial declaratives with V2 in the corpus of Norwegian child language

\begin{tabular}{llll}
\hline Speaker & Files & Age & $\%$ of $b e$ \\
\hline Ina & Ina.01-09 & $1 ; 8.20-2 ; 2.12$ & $59.2 \%(61 / 103)$ \\
Ann & Ann.01-08 & $1 ; 8.20-2 ; 1.28$ & $76.1 \%(108 / 142)$ \\
Ole & Ole.01-08 & $1 ; 9.10-2 ; 2.12$ & $85.5 \%(189 / 221)$ \\
Investigator & Ole.14 & Adult & $23.5 \%(28 / 119)$ \\
\hline
\end{tabular}

${ }^{9}$ Rowland et al. (2003) find that the copula is the first acquired verb for nine of the 12 children, and the second for two of the other three children. However, they investigate combinations of $w h$-word and all verbs in questions, and thus they also count verbs that do not invert with the subject. 
According to Roeper (in press), children are sensitive to classes of categories. That is, children seem to be happy to accept grammars where rules only apply to certain subcategories or classes of a category, and do not generally make sweeping generalizations that apply e.g. to all nouns or all verbs. As an example, Roeper discusses V2 in English to V2 in a language like German. While English-speaking children learn V2 as a rule that is restricted to certain verb types, German-speaking children start out in the same way, but due to massive evidence in the input, they soon realize that $\mathrm{V} 2$ is a categorial rule in German which applies to all verbs. That is, English-speaking children learn V2 with $b e$, and do not automatically assume that the rule also applies to other verbs in the language (unless there is positive evidence). However, Roeper reports one interesting case of a child who for a brief period (about a week) overgeneralized V2 to the verbs call and mean, and he provides the following examples:

(67a) what calls that?

(67b) what means that?

This indicates that English-speaking children learn V2 with be, and instead of assuming that this verb is an exception and therefore lexically marked for inversion, they categorize be as part of a class of verbs (the class of informationally light verbs) and may overgeneralize within this class, to verbs such as call and mean. Note that these verbs mean more or less the same as be in (67).

Moreover, to explain some of the examples from section 2, where inversion appears with verbs such as work or squat in present-day English, I would like to argue that children do not only pay attention to a well-defined class containing a fixed number of verbs which always or usually trigger inversion. They must also be sensitive to the information value of a verb in relation to the subject in particular sentences. Syntactically, this means that speakers of English can still occasionally invoke the LowTopP in certain cases and move informationally light verbs to this projection when the subject conveys new information, resulting in $\mathrm{V} 2$ word order. This means that even quite unusual verbs may appear with inversion in present-day English. I am repeating here sentence (11) with the verb squat, which presumably is not lexically marked for inversion in speakers' I-language grammars. Yet, this sentence is grammatical to speakers of English, which indicates that this verb may still move to the LowTopP when it is stripped of its specific meaning and generally means the same as $b e$.

$\left(11^{\prime}\right) \quad$...inland from the small, pretty harbor town that's called a haven squats the town of Heart's Rock.

\section{Summary and conclusion}

In this paper I have discussed two types of inversion in present-day English, subjectauxiliary inversion in questions and so-called stylistic inversion in certain declaratives. 
Comparing these word order inconsistencies to word order variation found across the other Germanic languages, I have classified English as a mixed, albeit restricted, V2 grammar. Furthermore, I have presented a Split-CP model of clause structure where different clause types have different heads in the $\mathrm{C}$ domain, represented as various types of ForceP. Within an extended cue-based approach to acquisition and change, several micro-cues for V2 word order are developed, one for each clause type. According to this model, children are sensitive to individual clause types when acquiring word order involving the $\mathrm{CP}$ domain, and there should therefore be no overgeneralization from one clause type to another. This accounts for children's early acquisition of word order in different clause types, e.g. V2 in questions and (generally) non-V2 in declaratives in present-day English. This model may also be used to explain the loss of V2 in only one clause type in the history of English. A change in one ForceP head does not affect other heads in this domain, simply because children in the acquisition process pay attention to the micro-cues.

Furthermore, children are argued to have an early sensitivity to information structure and to easily learn word order variation within clause types that is dependent on distinctions between given vs. new information. However, when one word order becomes less frequent in the input, the cue for this may drop below a critical level for acquisition. In this process, children pay attention to further micro-cues that involve even finer distinctions between natural classes of categories or subcategories. The verb be can be said to represent a separate class of verbs, and inversion with $b e$ is also acquired early in all V2 languages, including English. Children's distinction between classes of categories prevents them from overgeneralizing V2 to other classes of verbs. In this way, the remnant cases of $\mathrm{V} 2$ with be (and other informationally light verbs) may be considered to be due to early acquisition and children's sensitivity to natural classes of categories. Thus, from the perspective of the extended cue-based approach to acquisition and change, the word order inconsistencies of present-day English may in fact be considered to be the result of a standard kind of historical development.

\section{REFERENCES}

Anderssen, M. 2006. The acquisition of compositional definiteness in Norwegian. [Unpublished $\mathrm{PhD}$ dissertation, University of Tromsø.]

Bech, K. 2001. Word order patterns in Old and Middle English: A syntactic and pragmatic study. [Unpublished PhD dissertation, University of Bergen.]

Benincà, P. and C. Poletto. 2004. "Topic, Focus and V2: Defining the CP sublayers". In Rizzi, L. (ed.), The structure of CP and IP: The cartography of syntactic structures 2. Oxford and New York: Oxford University Press. 52-75.

Bentzen, K. 2005. "What's the better move? On verb placement in Standard and Northern Norwegian". Nordic Journal of Linguistics 28(2). 153-188.

Bhatt, R.M. 2004. "Indian English: Syntax". In Kortmann, B., K. Burridge, R. Mesthrie, E.W. Schneider and C. Upton (eds.), Handbook of varieties of English, vol. 2: Morphology and syntax. Berlin-New York: Mouton de Gruyter. 1016-1030. 
Biberauer, T. 2002. "Reconsidering embedded verb second: How 'real' is this phenomenon?". Working Papers in English and Applied Linguistics 8 (University of Cambridge, Research Centre for English and Applied Linguistics). 25-60.

Birner, B. 1995. "Pragmatic constraints on the verb in English inversion". Lingua 97. 233-256.

Bresnan, J. 1994. "Locative inversion and the architecture of Universal Grammar". Language 70. $72-131$.

Bresnan, J. and T. Nikitina. 2003. On the gradience of the dative alternation. [Ms., Stanford University.]

Bresnan, J. and T. Nikitina. To appear. "The gradience of the Dative Alternation”. In Uyechi, L. and L.H. Wee (eds.), Reality exploration and discovery: Pattern interaction in language and life. Stanford: CSLI Publications. (Revised version of Bresnan and Nikitina 2003.)

Brown, R. 1973. A first language: The early stages. Cambridge, MA: Harvard University Press.

Chomsky, N. 1986. Knowledge of language: Its nature, origin and use. New York: Praeger Publishers.

Clahsen, H. and K.-D. Smolka. 1986. "Psycholinguistic evidence and the description of V2 phenomena in German". In Haider, H. and M. Prinzhorn (eds.), Verb second phenomena in Germanic languages. Dordrecht: Foris. 137-168.

Clahsen, H., M. Penke and T. Parodi. 1993/1994. "Functional categories in early child German". Language Acquisition 3. 395-429.

den Besten, H., 1977. "On the interaction of root transformations and lexical deletive rules". [Ms., University of Amsterdam.] (Published 1981 in Groninger Arbeiten zur Germanistischen Linguistik 20. 1-78. Republished 1983 in Abraham, W. (ed.), On the formal syntax of the Westgermania. Amsterdam, John Benjamins. 47-131. Republished 1989 in den Besten, H. Studies in Germanic Syntax. Amsterdam: Rodopi. 14-100.)

Haeberli, E. 2002. "Inflectional morphology and the loss of verb-second in English". In Lightfoot, D. (ed.), Syntactic effects of morphological change. Oxford-New York: Oxford University Press. 88-106.

Henry, A. 1994. "Viewing change in progress: The loss of V2 in Hiberno-English imperatives". In Kemenade, A. van and N. Vincent (eds.), Parameters of morphosyntactic change. Cambridge: Cambridge University Press. 273-296.

Hróarsdóttir, T., G. H. Hrafnbjargarson, A.-L. Wiklund and K. Bentzen. 2006. "The Tromsø guide to Scandinavian verb movement". Working Papers in Scandinavian Syntax 78. 1-36.

Kemenade, A. van. 1987. Syntactic case and morphological case in the history of English. Dordrecht: Foris.

Kroch, A. and A. Taylor. 1997. "Verb movement in Old and Middle English: Dialect variation and language contact". In Kemenade, A. van and N. Vincent (eds.), Parameters of morphosyntactic change. Cambridge: Cambridge University Press. 297-325.

Levin, B. and M. Rappaport-Hovav. 1995. Unaccusativity: At the syntax-lexical semantics interface. Cambridge, MA: MIT Press.

Lightfoot, D. 1999. The development of language: Acquisition, change and evolution. Malden, MA-Oxford: Blackwell.

Lightfoot, D. 2006. How new languages emerge. Cambridge: Cambridge University Press.

MacWhinney, B. 2000. The CHILDES Project: Tools for analyzing talk. (3rd ed., vol. 2: The database.) Mahwah, NJ: Lawrence Erlbaum Associates.

Pintzuk, S. 1991. Phrase structures in competition: Variation and change in Old English word order. [Unpublished PhD dissertation, University of Pennsylvania.]

Poletto, C. 2006. "Old Italian scrambling: The low left periphery of the clause". In: Brandt, P. and E. Fuss (eds.), Form, structure and grammar: Studia Grammatica 63. 209-228. 
Prince, E.F. 1992. "The ZPG letter: Subjects, definiteness, and information-status". In Thompson, S.A. and W.C. Mann (eds.), Discourse description: Diverse linguistic analyses of a fund-raising text. Amsterdam and Philadelphia: John Benjamins. 295-325.

Radford, A. 1992. "The acquisition of the morphosyntax of finite verbs in English". In Meisel, J.M. (ed.), The acquisition of verb placement: Functional categories and V2 phenomena in language acquisition. Dordrecht: Kluwer. 23-62.

Radford, A. 1994. "The syntax of questions in child English". Journal of Child Language 21. 211-236.

Rizzi, L. 1996. "Residual verb second and the wh-criterion". In Belletti, A. and L. Rizzi (eds.), Parameters and functional heads. Oxford: Oxford University Press. 63-90.

Rizzi, L. 1997. "The fine structure of the left periphery". In Haegeman, L. (ed.), Elements of grammar: Handbook of generative syntax. Dordrecht: Kluwer. 281-337.

Rizzi, L. 2001. "On the position 'Int(errogative)' in the left periphery of the clause". In Cinque, G. and G. Salvi (eds.), Current studies in Italian syntax. Amsterdam: Elsevier. 287-296.

Roeper, T. 1999. "Universal bilingualism". Bilingualism: Language and Cognition 2(3). 169186.

Roeper, T. 2007. "What frequency can do and what it can't". In Gülzow, I. and N. Gagarina (eds.), Frequency effects in language acquisition: Defining the limits of frequency as an explanatory concept. (Studies on language acquisition.). Berlin: Mouton de Gruyter. 23-48.

Rowland, C.F. and J.M. Pine. 2000. "Subject-auxiliary inversion errors and wh-question acquisition: 'What children do know?"'. Journal of Child Language 27. 157-181.

Rowland, C.F. and J.M. Pine. 2003. "The development of inversion in wh-questions: A reply to Van Valin”. Journal of Child Language 30. 197-212.

Rowland, C.F., J.M. Pine, E.V.M. Lieven and A.L. Theakston. 2003. "Determinants of acquisition order in wh-questions: Re-evaluating the role of caregiver speech". Journal of Child Language 30. 609-635.

Salvi, G. 2005. "Some firm points on Latin word order: The left periphery". In Kiss, K.É. (ed.), Universal grammar in the reconstruction of ancient languages. Berlin: Mouton de Gruyter. 429-456.

Salvi, G. Forthcoming. "Morphosyntactic persistence from Latin into Romance". Cambridge History of the Romance Languages.

Swan, T. 1994. "A note on Old English and Old Norse initial adverbials and word-order with special reference to sentence adverbials". In Swan, T., E. Mørck and O.J. Westvik (eds.), Language change and language structure. (Trends in Lingustics 73.) Berlin: Mouton de Gruyter. 233-270.

Van Valin, R.D. 2002. "The development of subject-auxiliary inversion in English wh-questions: An alternative analysis". Journal of Child Language 29. 161-175.

Vangsnes, Ø.A. 2005. "Microparameters for Norwegian wh-grammars". Linguistic Variation Yearbook 5. Amsterdam and Philadelphia: John Benjamins. 187-226.

Westergaard, M.R. 2003. "Word order in wh-questions in a North Norwegian dialect: Some evidence from an acquisition study". Nordic Journal of Linguistics 26(1). 81-109.

Westergaard, M.R. 2005a. "Norwegian child language and the history of English: The interaction of syntax and information structure in the development of word order". In McCafferty, K., T. Bull and K. Killie (eds.), Contexts - Historical, social, linguistic. Studies in celebration of Toril Swan. Bern: Peter Lang. 293-410.

Westergaard, M.R. 2005b. "Optional word order in wh-questions in two Norwegian dialects: A diachronic analysis of synchronic variation”. Nordic Journal of Linguistics 28(2). 269-296.

Westergaard, M.R. 2006. "Triggering V2: The amount of input needed for parameter setting in a Split-CP model of word order”. In Belletti, A., E. Bennati, C. Chesi, E. DiDomenico and I. 
Ferrari (eds.), Language acquisiton and development: Proceedings of GALA 2005. Cambridge: Cambridge Scholars Press. 564-577.

Westergaard, M.R. 2007. "Learning and unlearning V2: On the robustness of the triggering experience in a historical perspective". In Picchi, M.C. and A. Pona (eds.), Proceedings of the XXXII Incontro di Grammatica Generativa. Alessandria: Edizioni dell'Orso. 193-207.

Westergaard, M. and K. Bentzen. 2007. "The (non-) effect of input frequency on the acquisition of word order in Norwegian embedded clauses". In Gülzow, I. and N. Gagarina (eds.), Frequency effects in language acquisition: Defining the limits of frequency as an explanatory concept. (Studies on language acquisition.) Berlin-New York: Mouton de Gruyter. 271306.

Westergaard, M.R. and Ø.A. Vangsnes. 2005. “Wh-questions, V2, and the left periphery of three Norwegian dialects”. Journal of Comparative Germanic Linguistics 8. 117-158. 